\title{
THE USE OF INDUSTRIAL NETWORKS TO STRENGTHEN CIVIL AND STRUCTURAL ENGINEERING EDUCATION; A SURVEY-BASED INVESTIGATION
}

\author{
Anette HEIMDAL, Ingrid Lande LARSEN and Rein Terje THORSTENSEN \\ University of Agder, Norway
}

\begin{abstract}
This paper investigates how the involvement of university and students into industrial networks might gain both continuous development of education programmes, and the learning outcomes of students within engineering education.

Involvement of the civil and structural engineering education in the creation and early operation of an industrial network - the local division of "Young Professionals' Concrete Network" - is used as a case. "Young Professionals' Concrete Network" are regional networks related to the Norwegian Concrete Association. The intention is to create networks for young professionals and students, focusing on all aspects of the use of concrete materials within engineering and construction.

This paper is based on a survey executed amongst civil engineering students that have participated in the local division of the network. The scope of the survey was to identify dividends generated from engaging in the network. The participants were asked to answer questions regarding outcomes from participation in different types of activities.

The results from the survey identified learning outcomes and other dividends from participation in a network that includes students, university employees, and young professionals from the industry. These findings are discussed to gain knowledge on how network engagement can be utilised to continuously improve the civil and structural engineering education and to strengthen the competence of participating students and young professionals. As the network is originating and run by stakeholders within the university, the generated knowledge is also used in a feedback loop for improvement of the activities offered by the network.
\end{abstract}

Keywords: Industrial network, survey, civil and structural engineering education, learning outcome, young professionals' concrete network

\section{INTRODUCTION}

Involvement of industry into educational programmes at universities is often claimed for having the potential to improve education. In an article presented at E\&PDE 2018 [1], a case on cooperation between industry and civil and structural engineering education is used for discussing how this improvement is facilitated. It is concluded that industrial involvement promotes real-life tasks for students and makes the capstone courses socially relevant. This motivates students. Additionally, involvement is shown to improve dialogue and correspondingly to secure update of the educational programmes, which is important for the university to continue educating professionals with relevant competence for working life. However, still referring to Thorstensen et al. (2018), it is also claimed that there are severe cultural barriers between industry and university [1]. To promote success, it is important to build bilateral awareness on these barriers and to act to reduce them.

Corresponding discussions and conclusions are easily found in the research environment, e.g., Tener (1996) claims that having effective cooperation between university and industry have the potential for gaining both the university and the industry [2]. Ankra and Al-Tabba (2015) argue that through university-industry collaboration, students are exposed to practical problems and new ideas and that the relationship may also lead to training and employment opportunities [3]. Metrejean (2002) found that the use of guest speakers also contributes to benefit the university; faculty members can get in 
contact with professionals resulting in cooperation, and it confirms the impression that the university is up-to-date and listens to the industry [4]. Payne et al. (2003) argue that guest speakers are beneficial for the students; they open the students' mind and bring the outside workplace into the classroom [5]. Tener (1996) highlights several characteristics of valuable industry-university cooperation, two of them being involving practitioners in the classroom and using internship programmes [2]. Industry and universities function differently, as industry has a much higher pressure for quick results than the universities [3]. This can lead to result-oriented, short-term research instead of long-term strategic competence building. These are all obstacles that must be addressed for the cooperation to be mutually beneficial.

Another way of involving industry and giving students higher practical competence and motivation is excursions and field trips to construction sites or fabrication facilities. This has proven to get the students more engaged in the learning process, increase their motivation, and to be a reinforcement to traditional classroom instruction [5]. However, there are often limited possibilities of excursions and field trips as part of normal study courses, as organising and execution are time and resource consuming.

Often, research on these topics is focused on impact from single actions and performances, like guest lectures and site visits. However, long-term cooperation between industry and university have the potential for generating even higher values. Svennevig \& Thorstensen (2018) proposed the concept of "Extra Curriculum", where the industry offers courses that are considered vital by the industry but is not a part of the educational programme [6].

Trust and bilateral knowledge are vital to all forms of dialogue. Those values are best created through continuous interaction and collaboration. In this paper, we focus on how involvement in an industrial network has the potential for strengthening the civil and structural engineering education. The objective is to identify learning outcomes and other dividends generated from engaging in the network.

\section{CASE}

To investigate the benefits of involvement, the newly established "Young Professionals' Concrete Network" (YPCN) in Agder is used as a case. YPCN is organised in regional networks, under the provision of the Norwegian Concrete Association. These regional networks are organised and run by volunteers at a growing number of locations. This national initiative intends to expand knowledge and create networks for young professionals, focusing on all aspects of the use of concrete materials within engineering and construction. Network activities are offered after school hours and are not part of the study programme. The activities offer opportunities to extend learning through participation in field trips, excursions, lectures on relevant topics given by industrial representatives, and participation in professional discussions. Another aspect is that the members can use these activities to create and maintain personal networks.

During the fall of 2018, a local branch of YPCN was established in our region. The establishment was initiated and executed by stakeholders at the civil and structural engineering education at the university, in cooperation with the local industry. Members are recruited amongst both students and industrial employees in the early stages of their career. Typical activities of the network are lectures on requested topics, industrial demonstrations, and excursions to construction sites and fabrication facilities.

YBCN-Agder arranges frequent events during the year, focusing on different aspects of the use of concrete materials within engineering and construction. Up to now, four activities have been executed:

- Startup; industrial lectures on two topics, followed by discussions in a social environment

- Excursion to a nearby highway under construction

- Excursion to a building site, expanding the university

- Excursion to a concrete element fabrication facility

YPCN include members from both industry and university (students). This mixing of people all in the early stages of their career is a carefully chosen strategic choice to promote mutual involvement between industry and university.

All students that participated in one or more of these events received a questionnaire. It would have been interesting also to include participants from the industry. However, these were left out this time, due to potential GDPR-conflicts. The participants were asked to answer questions regarding outcomes from participation in different types of activities. 


\section{METHODS}

A web-based survey was established, using the questionnaire tool offered by the software SurveyXact. The questionnaire was distributed to students at both bachelor and master level, as both are equally participating in YPCN-Agder. A total of 11 questions were asked, including some basic questions considering age, gender, and educational background.

The survey was distributed to 47 students. All received an invitation by e-mail, containing a link to the questionnaire. Five days after distribution, a reminder was sent. Those who still had not responded were personally contacted and encouraged to participate. The survey was distributed $20^{\text {th }}$ February 2019 and remained open until $1^{\text {st }}$ March 2019.

\section{RESULTS \& DISCUSSION}

After the first reminder, 19 of a total of 47 students had still not completed the questionnaire. The personal follow-up turned out successful. Conclusively, $100 \%$ of the included respondents finally completed and submitted the questionnaire.

Engineering students span wide in demographic status. To achieve a representative evaluation on students' effects of participation in the network activities, it was considered vital that the respondents spanned representatively to the total student population on demographic indicators; gender, age, educational background and progress in the engineering education. Information about the respondents is given in Table 1 .

Table 1. General information about the respondents

\begin{tabular}{|c|c|c|}
\hline Characteristics & Number of students & Percentage \\
\hline \multicolumn{3}{|l|}{ Gender } \\
\hline Male & 25 & 53.2 \\
\hline Female & 22 & 46.8 \\
\hline \multicolumn{3}{|l|}{ Age } \\
\hline 18 to 20 & 7 & 14.9 \\
\hline 21 to 25 & 20 & 42.6 \\
\hline 26 to 30 & 12 & 25.5 \\
\hline 31 to 35 & 4 & 8.5 \\
\hline Above 36 & 4 & 8.5 \\
\hline \multicolumn{3}{|l|}{ Educational background (prior to engineering) } \\
\hline Upper secondary school & 18 & - \\
\hline Technical school & 6 & - \\
\hline Preliminary course for engineers & 0 & - \\
\hline Completed Apprenticeship, Craft Certificate & 7 & - \\
\hline Other high education & 25 & - \\
\hline None of the above & 2 & - \\
\hline \multicolumn{3}{|l|}{ Education level } \\
\hline Bachelor $1^{\text {st }}$ year & 13 & 27.7 \\
\hline Bachelor $2^{\text {nd }}$ year & 7 & 14.9 \\
\hline Bachelor $3^{\text {rd }}$ year & 6 & 12.8 \\
\hline Master $1^{\text {st }}$ year & 12 & 25.6 \\
\hline Master $2^{\text {nd }}$ year & 7 & 14.9 \\
\hline
\end{tabular}

As all students attending YPCN-Agder events answered the questionnaire, the response can be claimed to fully represent the students that have participated in these activities. We do not have access to a verified model on all requested demographic data for the total population of students at the civil and structural engineering programme. Hence, we cannot conclude mathematically on representativity. The only indicator fully known to us is the gender distribution. The respondents are representative of the total student population on the programme when it comes to this indicator. All other requested indicators span widely between the respondents, in accordance with our estimates on the total population. Hence, it is concluded that the participants on YPCN-Agder activities are near representative of the total student population on the demographic indicators. 
It can not necessarily be claimed that participants are representative of the total population in all other aspects. We consider it reasonable that participation in activities additional to the compulsory curriculum might be more attractive to well-motivated students than others. Consequently, findings cannot be claimed to be representative of the total student population in the programme. But we consider results from this investigation to be representative for students who are well-motivated, on outcomes from participating in industrial network activities. Not all students are expected to participate in YPCN as activities focus on concrete, and this topic might not be central to all students' main interest.

The following discussion is considered to be representative for well-motivated students at the civil and structural engineering education generally, without focusing on the specific topic of YPCN.

Excursions are often known to be offered as part of specific courses and hence are distributed over different years ("classes") of the programme. Students in the higher classes of the programme have then been offered higher numbers of excursions. Participation in excursions offered as part of the education is presented in figure 1, left part: $19 \%$ of the respondents confirm to have participated in more than five excursions as part of their education. Correspondingly, $15 \%$ of the respondents claim to be in the $5^{\text {th }}$ year of the programme. Conclusively, there seems to be a good correlation that students in higher classes have participated in a higher number of excursions. $45 \%$ of the respondents confirm to have participated in 2-4 excursions, and 54\% of the students are in class 2-4. This covariation could be understood as excursions are normally offered once a year, and most students participate. At first glance, the participation at lower classes seems a bit more surprising; $28 \%$ of the student's state that they attend the first class, yet only $21 \%$ have participated excursions. One could expect that the curiosity on the future work environment would be very high at early stages in education. However, some students have real-life experience from work before university education, and these students might not be interested in typical early-stage excursions simply aiming at experiencing a construction site.

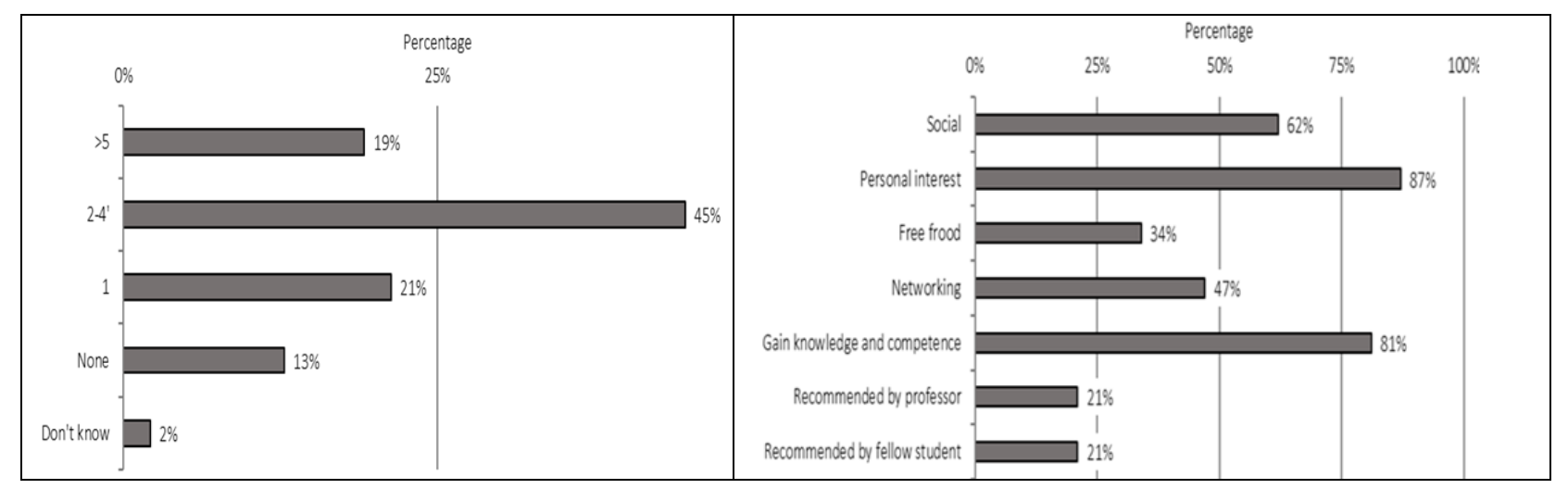

Figure 1. Left part: Participation in activities offered as part of the education.

Right part: Reasons for participating in YPCN-Agder excursions (multi-response question, allowing the respondent to choose several alternatives)

$85 \%$ of the respondents confirmed that they had participated in one or more excursions as part of their education. The university states that excursions are considered important for education. The results of this investigation confirm that excursions are offered as part of the programme. Conclusively, a high degree of participation is taken as confirmation that excursions are considered by students to be valuable parts of the education.

Figure 1 right part presents the respondents' reasons for participating in YPCN-Agder activities, which are additional to what is offered as part of the education. Both personal and professional interest is scored more than $80 \%$, constituting the main reason for participation. Students also seem to value these activities high for social reasons (immediate social value $62 \%$ and networking 47\%). Free food seems to be less important but still valued by the students. Less than $50 \%$ state that they participate because somebody recommended it. This, together with the high scores on professional and social value, indicates that students participate driven by personal motivation. Motivation is known to be vital for the successful completion of education.

The respondents were also asked to rank the motivational outcome in ongoing study work from participation in YPCN-Agder activities on a scale from 1 (very low motivational factor) to 5 (very 
high motivational factor). $66 \%$ ranked the motivational outcome as "high" or "very high". Only $8 \%$ ranked it "low" or "very low" (Figure 2). The average outcome is 3.84 - well within the category "high motivational outcome".

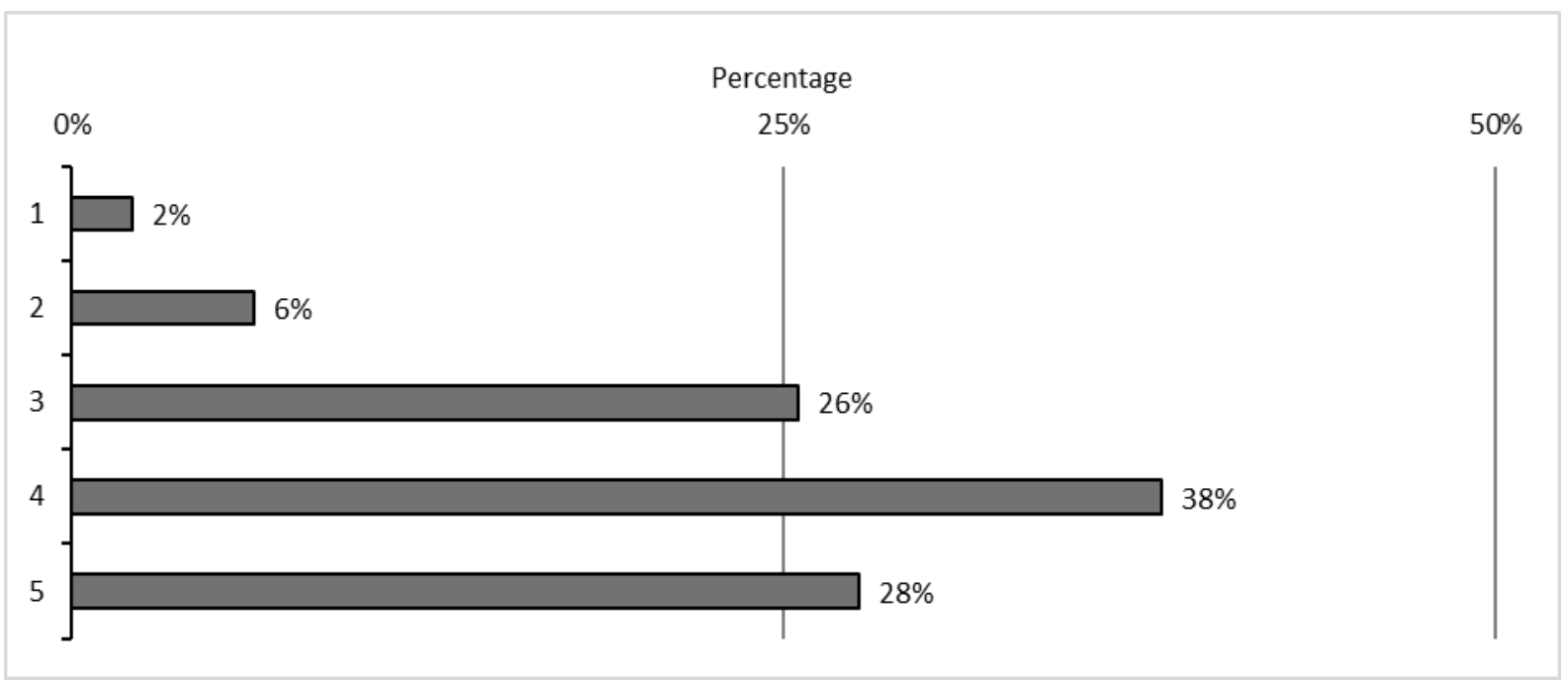

Figure 2. Contribution to motivation in ongoing study work ranked from 1 (very low motivational factor) to 5 (very high motivational factor)

A similar study was done by Metrejean in 2010 [4]; a survey is questioning the students' outcome from guest speakers. When questioned about the benefits of the guest speaker, they got an average of 4.06 out of a scale from 0 to 5, where 0 meant no benefit and 5 meant extreme benefit. This indicated clearly that the use of guest speakers was very beneficial for the students. By using guest speakers, the students will receive first-hand knowledge by professionals, and it also allows informal networking.

Our results also correspond with Payne et al. (2003) [5], who has shown that contribution in field trips increase the students' interest in a subject and comprehend of the subject matter. According to this study, if the student is more of a dynamic learner, who easily lose their concentration in passive learning situations, this can allow them to participate more actively by exploring. The research also indicates that students remember nine times more of what they say and do compare to what they read. Field trips can, therefore, give some students a better understanding and help them learn more about different subjects [5].

\section{CONCLUSIONS}

1. Students value participation in network activities as "highly motivational" regarding their ongoing study work.

2. University considers real-life involvement in the educational programme to be of high value, both because of professional content and because of the motivational value it has to students. The present investigation confirms the relevance of this view.

3. The mixed environment of students and young professionals offered through the industrial network (YPCN), is ranked highly by students for the educational value. University considers these networks as important extensions of the learning environment.

4. Students participating in the industrial network "Young Professionals' Concrete Network" (YPCN) are found to be representative for the total student population at the Civil and Structural Engineering programme when it comes to demographic status.

5. The survey included all students that participated in YPCN-Agder activities, and the response was $100 \%$. Hence, responses are representative of all participating students.

6. Participation in network activities might be more attractive to well-motivated students than others. Hence, findings cannot be claimed to be representative of the total student population. But findings on values of participating in industrial network activities are believed to be representative to students who are well motivated. Motivated students who have not participated in YPCN activities might not be interested in concrete but are believed to gain correspondingly from activities within subjects more central to their main interests. 
7. The high degree of participation on excursions offered as part of the education is taken as confirmation that students consider these activities to be valuable parts of the education.

8. Engineering student participation in diverse network activities in a mixed group of students and young professional engineers state the following reasons for repeated participation: $80-90 \%$ personal and professional interest and 50-60\% social interest and networking.

\section{REFERENCES}

[1] Thorstensen R.T., Svennevig P.R. and Larsen I.L. "Pursuing diversity in engineering education; a case study on R\&DI-cooperation within civil engineering," in DS 93: Proceedings of the 20th International Conference on Engineering and Product Design Education (E\&PDE 2018), Dyson School of Engineering, Imperial College, London. 6th-7th September 2018, 2018, pp. 181-186.

[2] Tener R.K. "Industry-university partnerships for construction engineering education," Journal of Professional Issues in Engineering Education and Practice, vol. 122, no. 4, pp. 156-162, 1996.

[3] Ankrah S. and Al-Tabbaa O. "Universities-industry collaboration: A systematic review," Scandinavian Journal of Management, vol. 31, no. 3, pp. 387-408, 2015/09/01/ 2015.

[4] Metrejean C., Pittman J. and Zarzeski M.T. "Guest speakers: reflections on the role of accountants in the classroom," Accounting Education, vol. 11, no. 4, pp. 347-364, 2002/12/01 2002.

[5] Payne B.K., Sumter M. and Sun I. "Bringing the field into the criminal justice classroom: Field trips, ride-alongs, and guest speakers," Journal of Criminal Justice Education, vol. 14, no. 2, pp. 327-344, 2003/11/01 2003.

[6] Svennevig P.R. and Thorstensen R.T. "Extra curriculum, civil and structural engineering studies at University of Agder, Norway," in DS 93: Proceedings of the 20th International Conference on Engineering and Product Design Education (E\&PDE 2018), Dyson School of Engineering, Imperial College, London. 6th-7th September 2018, 2018, pp. 512-517. 